\title{
Degradation of Leakage Currents and Reliability Prediction for Tantalum Capacitors
}

\author{
Alexander Teverovsky, AS\&D, Inc., work performed for NASA Goddard Space Flight Center
}

Key Words: acceleration factors, degradation, failures, leakage current, tantalum capacitors

\section{SUMMARY \& CONCLUSIONS}

Two types of failures in solid tantalum capacitors, catastrophic and parametric, and their mechanisms are described. Analysis of voltage and temperature reliability acceleration factors reported in literature shows a wide spread of results and requires more investigation.

In this work, leakage currents in two types of chip tantalum capacitors were monitored during highly accelerated life testing (HALT) at different temperatures and voltages.

Distributions of degradation rates were approximated using a general log-linear Weibull model and yielded voltage acceleration constants $B=9.8 \pm 0.5$ and 5.5. The activation energies were $E_{a}=1.65 \mathrm{eV}$ and $1.42 \mathrm{eV}$. The model allows for conservative estimations of times to failure and was validated by long-term life test data.

Parametric degradation and failures are reversible and can be annealed at high temperatures. The process is attributed to migration of charged oxygen vacancies that reduce the barrier height at the $\mathrm{MnO} 2 / \mathrm{Ta} 2 \mathrm{O} 5$ interface and increase injection of electrons from the $\mathrm{MnO} 2$ cathode. Analysis showed that the activation energy of the vacancies' migration is $\sim 1.1 \mathrm{eV}$.

\section{INTRODUCTION}

Two types of failures are known for solid chip tantalum capacitors with manganese oxide cathodes operating at steady state conditions. Type I appears as a sharp rise of direct current leakage (DCL) indicating breakdown of the dielectric, and type II as a gradual increase of currents with time resulting in parametric failures.

Failures in tantalum capacitors are often explained by fieldinduced crystallization of the amorphous anodic tantalum pentoxide dielectric $[1,2]$. These crystals gradually grow with time of operation under the amorphous Ta2O5 layer and eventually disrupt the dielectric.

Type I failures can be explained based on the time dependent dielectric breakdown (TDDB) model [3]. According to the thermochemical model, the breakdown occurs when the local electrical field weakens polar molecular bonds with time to the level at which thermal energy is sufficient to cause the breakage.

Type II failures appear as a gradual degradation of DCL with time that might eventually exceed the specified limit. Experiments showed that in some capacitors currents might increase with time by several orders of magnitude and result eventually in a thermal runaway and catastrophic failures. The process was explained by migration of positively charged oxygen vacancies in the Ta2O5 dielectric $[4,5]$.

The voltage acceleration factor for reliability calculations that is determined as a ratio of failure rates at the test and rated (VR) voltages, can be written in the form:

$$
A F_{V}=\exp \left[B \times\left(\frac{V_{\text {test }}}{V R}-1\right)\right],
$$

where $B$ is the voltage acceleration constant.

The temperature acceleration factor is determined as a ratio of failure rates measured at temperatures $T_{1}$ and $T_{2}$ and is described by the Arrhenius equation:

$$
A F_{T}=\exp \left[-\frac{E_{a}}{k} \times\left(\frac{1}{T_{1}}-\frac{1}{T_{2}}\right)\right],
$$

where $k=8.617 \times 10^{-5} \mathrm{eV} / \mathrm{K}$ is the Boltzmann constant, and $E_{a}$ is the activation energy.

Only scarce information was found in the literature about reliability acceleration factors for tantalum capacitors, and most of the existing data are related to catastrophic, type I, failures. Table 1 shows values of $B$ and $E_{a}$ for type I and type II failures estimated based on technical publications. Constant B for type I failures varies in a wide range, from 6 to 20.6 and activation energies are in the range from $0.7 \mathrm{eV}$ to $2.1 \mathrm{eV}$. At these ranges, a $20 \%$ change of operating voltage, would cause variation of $A F_{V}$ by more than an order of magnitude, from 3.3 to 61.5. Temperature increase from a typical operating conditions of 55 ${ }^{\circ} \mathrm{C}$, to test conditions at $125{ }^{\circ} \mathrm{C}$, would vary $A F_{T}$ from 78 to $4.7 \times 10^{5}$.

Assessment of failure rates in military grade tantalum capacitors is based on the assumption that the constant $B$ is the same for all part types, $B=18.77$. However, analysis [6] showed that this assumption can cause errors in FR up to three orders of magnitude because actual values of $B$ can vary substantially from lot to lot. This requires development of express methods to assess acceleration factors for different types of capacitors. One such method that has been suggested in [3] is based on measurements of breakdown voltages and the TDDB model. Another express method is based on analysis of times to failures (TTF) observed during life step stress testing [7].

These methods were used for type I, or catastrophic failures that are typically detected by blown fuses connected in series with each capacitor under test during burning-in or so called 
Weibull grading testing. Type II failures are often observed during qualification life tests that are carried out at $125^{\circ} \mathrm{C}$ and require periodic measurements of leakage currents during the test.

This work was undertaken to evaluate acceleration factors for reliability testing based on the rate of degradation of leakage currents.

\begin{tabular}{|c|c|c|c|c|}
\hline Type & $B$ & $E_{a}, e V$ & Comments & Ref. \\
\hline I & $9.3-16.1$ & 1.2 & $\begin{array}{l}\text { Different types of } \\
\text { capacitors }\end{array}$ & [1] \\
\hline I & & $1-1.2$ & MIM capacitors & [8] \\
\hline I & $6-18.2$ & $0.7-2.1$ & $\begin{array}{l}\text { Microchip } \\
\text { capacitors }\end{array}$ & [9] \\
\hline I & $10.9-12.6$ & $1.08-1.15$ & $\begin{array}{l}\text { KEMET } 10 \mu \mathrm{F} \\
16 \mathrm{~V} \text { capacitors }\end{array}$ & [10] \\
\hline I & $9.6-20.6$ & $1.1-2.1$ & $\begin{array}{l}\text { HALT at different } \\
\mathrm{T} \text { and } \mathrm{V}\end{array}$ & [7] \\
\hline I & 18.77 & 2.1 & $\begin{array}{l}\text { Based on MIL- } \\
\text { PRF-55365 }\end{array}$ & {$[6]$} \\
\hline I & 8.1 & 0.63 & $\begin{array}{l}\text { Factors suggested } \\
\text { by AVX }\end{array}$ & [11] \\
\hline I & & 1.45 & $\operatorname{TTF}(\mathrm{T})$ & [12] \\
\hline I & 14.7 & 1.17 & $\begin{array}{l}\text { Per KEMET data } \\
\text { sheets }\end{array}$ & [13] \\
\hline I & 7.2 & 0.62 & $\begin{array}{l}\text { Per HITACHI data } \\
\text { sheets }\end{array}$ & [14] \\
\hline I & 6.8 & 0.66 & $\begin{array}{l}\text { Per NEC/TOKIN } \\
\text { data sheets }\end{array}$ & [15] \\
\hline II & & $\sim 2$ & $\begin{array}{l}\text { Rates of current } \\
\text { increase }\end{array}$ & [16] \\
\hline II & & $1.1-1.3$ & $\begin{array}{l}\text { Rate of annealing } \\
\text { and TSD }\end{array}$ & [17] \\
\hline
\end{tabular}

Table 1. Literature data for voltage acceleration constants and activation energies for type I and type II failures.

\section{TECHNIQUE}

Two lots of molded case chip $6.8 \mu \mathrm{F}$ tantalum capacitors rated to $25 \mathrm{~V}$ and $35 \mathrm{~V}$ were selected for this study based on preliminary tests showing that capacitors from these lots have substantial degradation of leakage currents at high temperatures. Twenty capacitors of each type were used for the HALT with monitoring of leakage currents at different temperatures and voltages. Each test consisted of 30 hours stress under bias followed by depolarization $(\mathrm{V}=0)$ at the same temperature for 3 hours. The testing was carried out at room temperature, $85^{\circ} \mathrm{C}, 105{ }^{\circ} \mathrm{C}, 125^{\circ} \mathrm{C}$ and $145^{\circ} \mathrm{C}$. For capacitors rated to $25 \mathrm{~V}$, stress voltages increased from $15 \mathrm{~V}$ to $25 \mathrm{~V}$, and finally to $35 \mathrm{~V}$. The currents were monitored by scanning voltages across $100 \mathrm{kohm}$ resistors connected in series with each capacitor.

Typical $I-t$ characteristics observed during the testing are shown in Figure1. A general trend for DCL variations is an initial decrease followed by increasing current degradation. The initial decrease is due to absorption currents that follow the empirical Curie - von Schweidler power law, $I \sim t^{-n}$, with the exponent $n$ close to 1 . These currents might be substantially larger than the intrinsic leakage currents even at $125^{\circ} \mathrm{C}$.

A portion of the $I-t$ curve with increasing currents was approximated with a linear function:

$$
I(t)=I_{0}+\alpha \times t
$$

where $I_{0}$ is the initial current, and $\alpha$ is the rate of degradation.

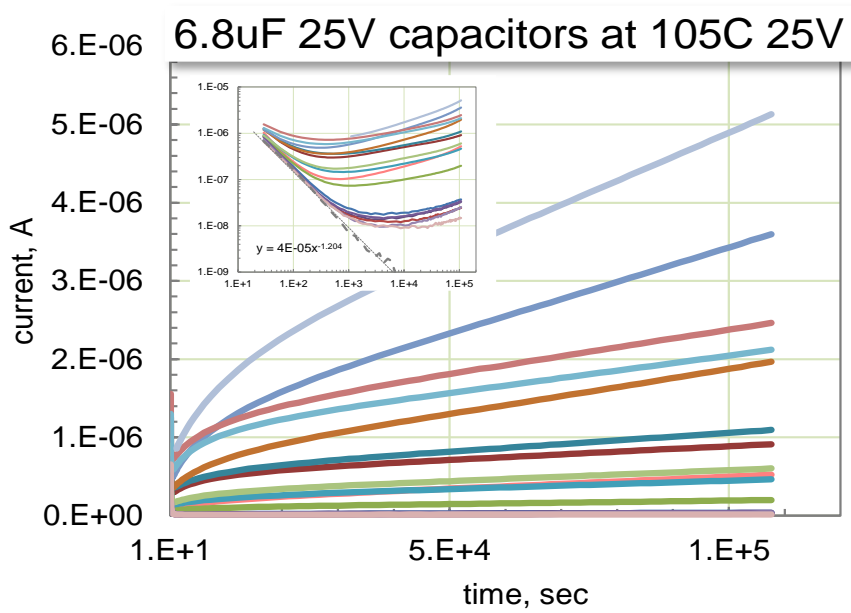

Figure 1. Variations of leakage currents with time at $105^{\circ} \mathrm{C}$, $25 \mathrm{~V}$. Insert shows the same chart in double logarithmic coordinates.

Rates of current degradation were calculated for each part at each test condition and distributions of $\alpha$ were approximated with Weibull law:

$$
F(\alpha)=1-\exp \left[-\left(\frac{\alpha}{\eta}\right)^{\beta}\right],
$$

where $\eta>0$ is the characteristic degradation rate (scale parameter), and $\beta>0$ is the shape parameter (slope).

The values of $\beta$ and $\eta$ were determined using a general loglinear model at a reciprocal transformation of absolute temperature. ALTA-7 software available from ReliaSoft was used to calculate parameters of the model based on the maximum likelihood estimation (MLE) method. According to this method, all distributions are assumed to have the same slopes of Weibull distributions, and the scale parameter depends on temperature and voltage as:

$$
\eta(T, V)=a_{0} \times \exp \left(\frac{a_{1}}{T}\right) \times \exp \left(a_{2} \times V_{\text {test }}\right),
$$

where $a_{i}$ are parameters of the model, and $T$ is the absolute temperature.

Based on the model's parameters, the voltage acceleration constant $B$ and the activation energy of degradation, $E_{a}$, can be calculated: $B=a_{2} \times V R$ and $E_{a}=-a_{1} / k$.

\section{TEST RESULTS}

An example of experimental data obtained during leakage current monitoring for a capacitor rated to $35 \mathrm{~V}$ at $85^{\circ} \mathrm{C}$ and different voltages and their linear approximations are shown in Figure 2. 


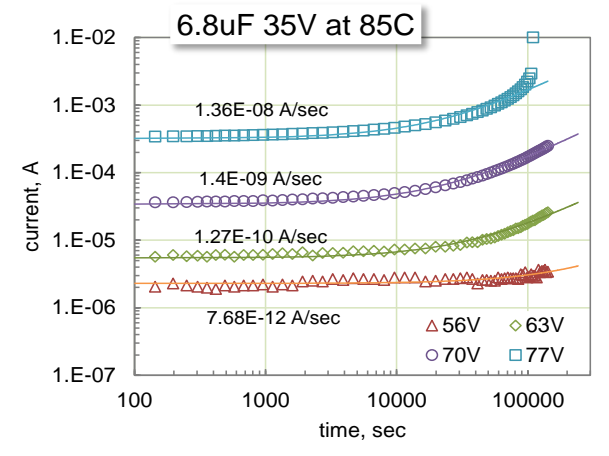

Figure 2. Variations of leakage currents with time in a $6.8 \mu \mathrm{F}$ $35 \mathrm{~V}$ capacitor at $85^{\circ} \mathrm{C}$ and different voltages. Marks correspond to experimental values, and lines are linear approximations.

The rate of degradation increased more than three orders of magnitude with voltage, from $\sim 7 \mathrm{E}-12 \mathrm{~A} / \mathrm{sec}$ at $56 \mathrm{~V}$ to more than $1 \mathrm{E}-8 \mathrm{~A} / \mathrm{sec}$ at $77 \mathrm{~V}$. Eventually, the part failed after $\sim 30$ hours of testing at $77 \mathrm{~V}$. The rate of degradation increased exponentially with voltage, and calculations for this sample yielded voltage acceleration constant $B=12.4$.

Degradation of currents with time at $125^{\circ} \mathrm{C}$ and different voltages for $6.8 \mu \mathrm{F}, 25 \mathrm{~V}$ capacitors is shown in Figure 3 . Currents increased linearly with time during the whole period of testing at $25 \mathrm{~V}$, but showed a trend for saturation at $35 \mathrm{~V}$. A similar trend was also observed at $145^{\circ} \mathrm{C}$ and $25 \mathrm{~V}$.

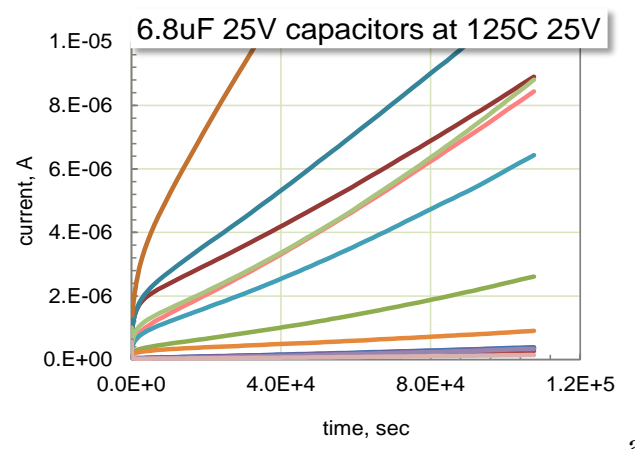

a)

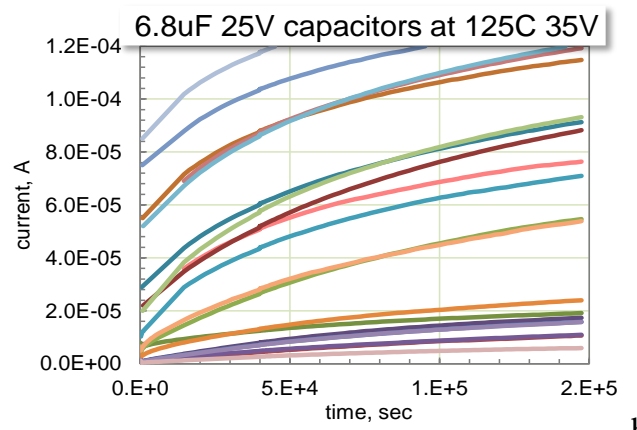

b)

Figure 3. Variations of currents with time during 30-hour steps at $125^{\circ} \mathrm{C} 25 \mathrm{~V}(\mathrm{a})$ and $125^{\circ} \mathrm{C} 35 \mathrm{~V}(\mathrm{~b})$.

Degradation rates calculated for $25 \mathrm{~V}$ capacitors at different temperatures are plotted against the minimal values of DCL, $I_{\min }$, in Figure 4. The results indicate a good correlation between these parameters and the possibility of selecting the most stable capacitors based on the level of initial currents. The values of $\alpha$ increase with $I_{\min }$ according to a power law with the exponent $\sim 1.4$.

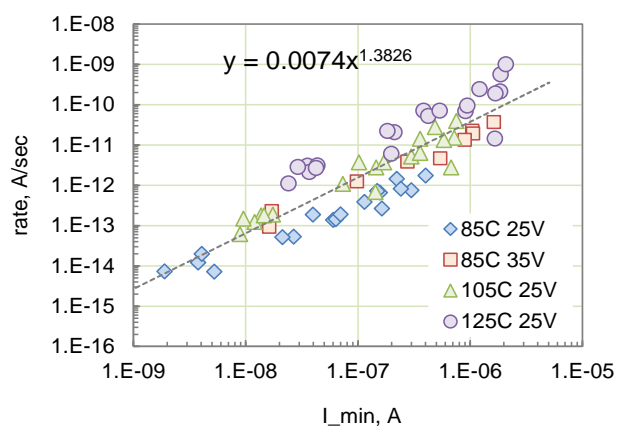

Figure 4. Correlation between the rate of degradation and minimal leakage currents for $6.8 \mu F 25$ V capacitors.

After testing of capacitors rated to $25 \mathrm{~V}$ at $125^{\circ} \mathrm{C}$ and 35 $\mathrm{V}$, leakage currents at $85^{\circ} \mathrm{C}$ and $25 \mathrm{~V}$ were monitored for 10 hours twice: immediately after the testing and then after baking at $175^{\circ} \mathrm{C}$ for 20 hours. No parametric failures were observed during the initial $85{ }^{\circ} \mathrm{C}$ testing, but all parts failed DCL requirements $(1.7 \mu \mathrm{A})$ when the measurements were made after HALT. Baking resulted in a substantial reduction of currents, and $\sim 90 \%$ of capacitors were within the specified limits after the bake. The baking cycle that included measurements of currents at $85^{\circ} \mathrm{C} 25 \mathrm{~V}$ right after HALT, annealing, and postbake measurements was repeated after the last 30-hours test at $25 \mathrm{~V}$ and $145^{\circ} \mathrm{C}$. To evaluate the effect of annealing duration, the $85^{\circ} \mathrm{C}$ measurements were carried out after 10,30 , and 60 hours of bake at $175^{\circ} \mathrm{C}$. Variations of currents measured at 25 $\mathrm{V}$ and $85{ }^{\circ} \mathrm{C}$ through the testing are shown in Figure 5 and indicate reproducible variations of leakage currents in the HALT-bake cycles. Leakage currents decrease with the time of baking and a 60 -hour bake at $175^{\circ} \mathrm{C}$ can completely restore the values of DCL observed before the testing even for samples that had currents degraded by almost three orders of magnitude.

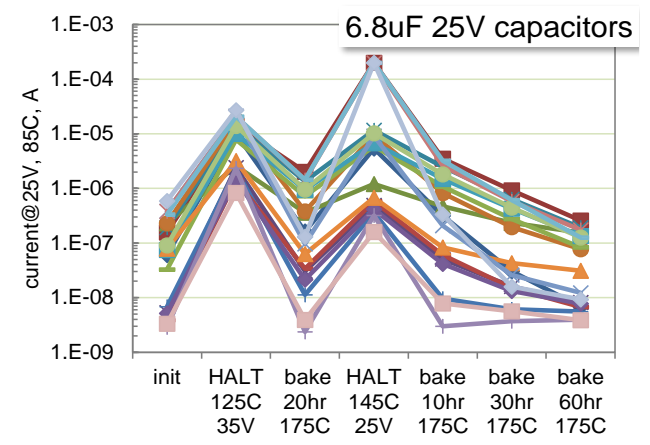

Figure 5. Variations of DCL measured at $85{ }^{\circ} \mathrm{C} 25 \mathrm{~V}$ through the HALT testing and bake.

\section{DISTRIBUTIONS OF DEGRADATION RATES AND TTF}

Results of calculations of the degradation rates during HALT at $25 \mathrm{~V}$ are shown in Figure 6. The distributions at different temperatures look similar and can be described using bi-modal Weibull laws indicating the presence of fast degrading and slow degrading subgroups in the population. Because we are interested in minimal times-to-failures, the subgroup with 
high rates is of the most interest. To simplify calculations in the following analysis, we consider samples in the slow-degrading subgroup (below 35\% of the distribution) and high-degrading subgroup (above $35 \%$ of the distribution) separately.

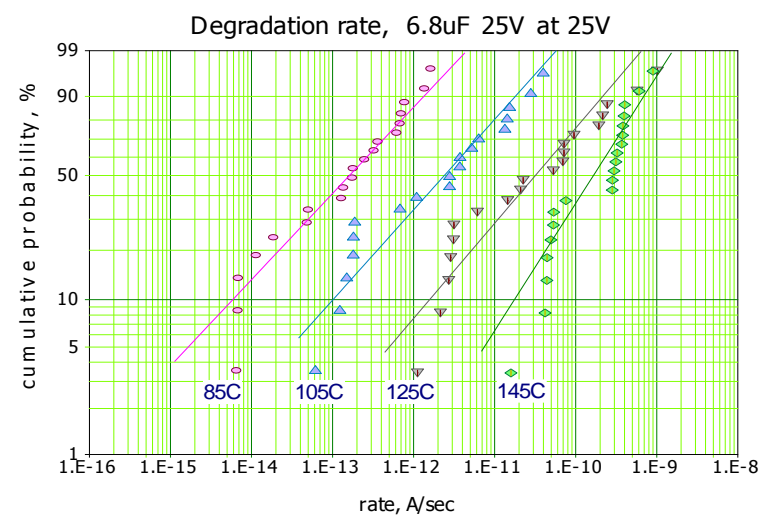

Figure 6. Distributions of degradation rates in $6.8 \mu \mathrm{F} 25 \mathrm{~V}$ capacitors at $25 \mathrm{~V}$ and temperatures from $85^{\circ} \mathrm{C}$ to $145^{\circ} \mathrm{C}$.

Distributions of $\alpha$ for $6.8 \mu \mathrm{F} 35 \mathrm{~V}$ capacitors were unimodal. These parts were tested similar to $6.8 \mu \mathrm{F} 25 \mathrm{~V}$ capacitors, but at voltages from $49 \mathrm{~V}$ to $77 \mathrm{~V}$ with $7 \mathrm{~V}$ increments at $85^{\circ} \mathrm{C}$, and at $125^{\circ} \mathrm{C}$ the measurements were made at $42 \mathrm{~V}$ only. Experimental data and results of modeling of HALT are shown in Weibull coordinates in Figure 7.

Degradation rates for $6.8 \mathrm{uF} 35 \mathrm{~V}$ capacitors

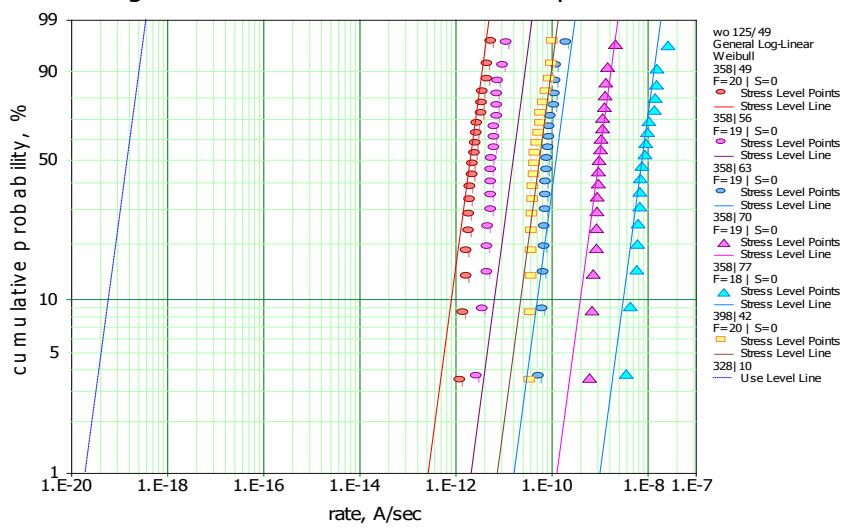

Figure 7. Distributions of degradation rates during HALT for $6.8 \mu F, 35 V$ capacitors at different temperatures and voltages. Marks correspond to experimental data and lines are approximation with the log-linear model. A dashed line corresponds to the "use life", $55^{\circ} \mathrm{C}, 10 \mathrm{~V}$, conditions.

Similar distributions were obtained for $6.8 \mu \mathrm{F} 25 \mathrm{~V}$ capacitors separately, for the fast-degrading and slowdegrading subgroups. Results of analysis using the log-linear model, Equation (5), as well as voltage acceleration constants and activation energies are displayed in Table 2. Constants $B$ and $E_{a}$ are similar for the slow-degrading subgroup of capacitors rated to $25 \mathrm{~V}$ and to $35 \mathrm{~V}$ capacitors $\left(B \_\right.$avr $=9.8$ \pm 0.5 and $E_{a \_}$avr $\left.=1.65 \pm 0.1 \mathrm{eV}\right)$. However, both constants are smaller ( $\sim 5 \%$ for $B$ and $\sim 20 \%$ for $E_{a}$ ) for the fast degrading subgroup.

Results of life testing for six samples of $6.8 \mu \mathrm{F} 25 \mathrm{~V}$ capacitors tested at $125{ }^{\circ} \mathrm{C}$ and $16.6 \mathrm{~V}$ for 2000 hours are presented at Figure8. Two out of six samples failed marginally, one after $1000 \mathrm{hrs}$ and another after $2000 \mathrm{hrs}$. Apparently, the currents are stabilizing after $\sim 1500 \mathrm{hrs}$, so it is quite possible that other parts in this group would not fail if testing continued.

\begin{tabular}{|c|c|c|c|}
\hline & \multicolumn{2}{|c|}{$6.8 \mu \mathrm{F} 25 \mathrm{~V}$} & $6.8 \mu \mathrm{F} 35 \mathrm{~V}$ \\
\hline & Low-rate & High-rate & All data \\
\hline$\beta$ & 1.46 & 0.99 & 1.95 \\
\hline$a_{0}$ & 12.59 & 12.53 & 12.298 \\
\hline$a_{1}$ & $-1,9300$ & $-1,6400$ & $-1,9150$ \\
\hline$a_{2}$ & 0.370 & 0.218 & 0.294 \\
\hline$B$ & 9.25 & 5.45 & 10.3 \\
\hline$E_{a}, \mathrm{eV}$ & 1.66 & 1.42 & 1.65 \\
\hline
\end{tabular}

Table 2. Parameters of log-linear model.

To validate the model, degradation rates at the life test conditions $\left(125{ }^{\circ} \mathrm{C}, 16.6 \mathrm{~V}\right)$ were calculated for the slowdegrading and fast degrading subgroups for $6.8 \mu \mathrm{F} 25 \mathrm{~V}$ capacitors, and times to failure were determined for each capacitor based on the linear approximation:

$$
T T F=\frac{I_{c r i t}-I_{0}}{\alpha},
$$

where $I_{\text {crit }}=40.8 \mu \mathrm{A}$ is the critical current at life test conditions.

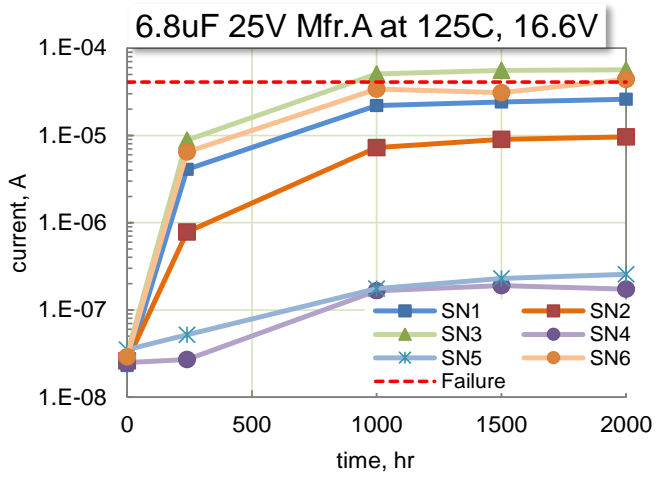

Figure 8. Variations of current with time for 6 samples of 6.8 $\mu F 25 V$ capacitors during life testing.

A comparison of times to failure calculated based on the model and experimental data obtained during life testing is shown in Fig.9. The calculated and experimental TTF data are close thus validating the model. However, calculations predict smaller times to failure, likely due to the saturation of currents and decreasing rate of degradation with time that was neglected in the model. The slope of the TTF distribution for the fastdegrading subgroup of capacitors is 1.96 , which indicates wearout type of failures.

The model was also used to assess TTF at the use conditions, $55^{\circ} \mathrm{C}$ and $10 \mathrm{~V}$. The relevant distribution is shown in Figure 9 and indicates that the probability of parametric failures is less than $1 \%$ after $~ 800$ years of operation. The results show a substantial, more than 5 orders of magnitude increase in the life expectancy as temperature and voltage decrease. The acceleration factor of life testing compared to the operating conditions was calculated based on Table 1 data: $\mathrm{AF}=\mathrm{AF}_{\mathrm{V}} \times \mathrm{AF}_{\mathrm{T}}=36 \times 6800=2.4 \times 10^{5}$. For these two conditions 
the acceleration caused by temperature is almost two orders of magnitude greater than by voltage.

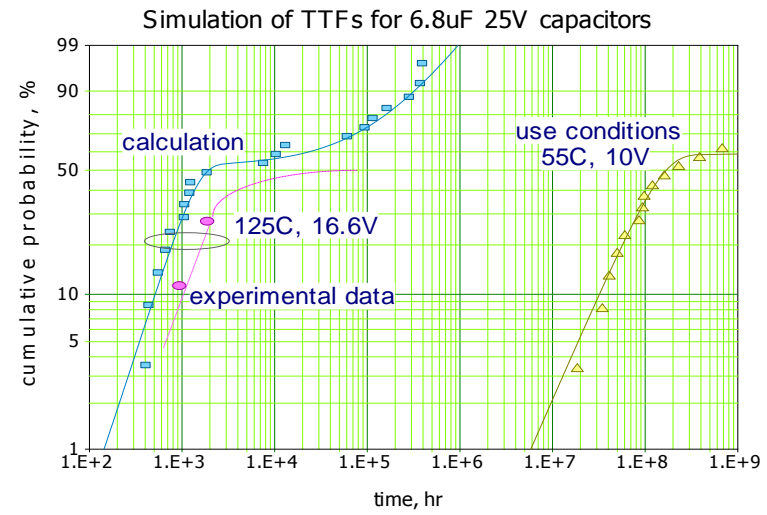

Figure 9. Distributions of the calculated and experimental times to failure. Experimental data correspond to results in Figure 8, and "calculation" is based on the results of HALT and log-linear model.

\section{DISCUSSION}

The reversibility of degradation of leakage currents that was also observed earlier [17] precludes the possibility of parametric failures caused by the field-induced crystallization of the Ta2O5 dielectric. The most probable cause of degradation is migration of positively charged oxygen vacancies, $\mathrm{V}_{\mathrm{o}}^{++}$. Under applied bias, oxygen vacancies move to the cathode, reduce the barrier at the $\mathrm{MnO} 2 / \mathrm{Ta} 2 \mathrm{O} 5$ interface, and increase injection of electrons into the dielectric by the Schottky mechanism. High-temperature annealing causes redistribution of $\mathrm{V}_{\mathrm{o}}^{++}$, thus increasing the barrier height, and decreasing leakage currents.

A variation of the normalized leakage currents with time during the degradation process depends on the effective surface charge density $Q_{s}(t)$ at the dielectric/cathode interface and can be written as [5]:

$$
\frac{I(t)}{I_{0}}=\exp \left[\frac{\beta_{s}}{k T}\left(\left(\frac{V_{\text {test }}}{d}+\frac{Q_{s}(t)}{\varepsilon_{0}}\right)^{0.5}-\left(\frac{V_{\text {test }}}{d}\right)^{0.5}\right)\right],
$$

where $\beta_{s}=2.71 \times 10^{24} \mathrm{C} \times(\mathrm{m} \times \mathrm{V})^{0.5}$ is the Schottky constant, $\varepsilon=$ 5 is the high frequency dielectric constant, $\varepsilon_{0}=8.85 \times 10^{-12} \mathrm{~F} / \mathrm{m}$ is the dielectric constant of vacuum, and $d$ is the thickness of Ta2O5 dielectric that for $25 \mathrm{~V}$ capacitors is $\sim 150 \mathrm{~nm}$.

Considering that during HALT at $125^{\circ} \mathrm{C}$ and $25 \mathrm{~V}$ the ratio $I_{\max } / I_{0}$ is $\sim 10^{3}$, calculations per Eq.(7) yielded $Q_{s} \sim 0.01 \mathrm{C} / \mathrm{m}^{2}$. Assuming that this charge was initially distributed evenly through the thickness of oxide, the concentration of $\mathrm{V}_{\mathrm{o}}^{++}$should be $\sim 4.2 \times 10^{17} \mathrm{~cm}^{-3}$ minimum. The actual concentration of $\mathrm{V}_{\mathrm{o}}^{++}$, $N_{v}$, is likely at least an order of magnitude greater, which corresponds to literature data [18].

In a first approximation, we can assume that at the beginning of the degradation process, the surface charge increases with time linearly:

$$
Q_{s}(t)=q \times \mu \times E \times N_{v} \times t,
$$

where $q=1.6 \times 10^{-19} \mathrm{C}$ is the electron charge, $\mu$ is the mobility of oxygen vacancies, and $E=V_{\text {test }} / d$ is the electric field.
It is possible to show that in this approximation, the degradation rate depends on the initial intrinsic current, $I_{0}(T)$, and mobility of oxygen vacancies:

$$
\alpha(T)=I_{0}(T) \times \frac{\beta_{s}}{k T} \times\left(\frac{V_{\text {test }}}{d}\right)^{0.5} \times \frac{q \times \mu(T) \times N_{v}}{2 \varepsilon \varepsilon_{0}},
$$

Both parameters in this equation, $I_{0}$ and $\mu$, are increasing with temperature according to the Arrhenius law, hence the activation energy of the degradation rate is a sum of activation energies of leakage currents, $E_{i}$, and $\mathrm{V}_{\mathrm{o}}^{++}$migration, $E_{v}$ :

$$
E_{a}=E_{i}+E_{v},
$$

Results of this work indicate $E_{a} \sim 1.65 \mathrm{eV}$, and based on the temperature dependence of $I_{\min }, E_{i}$ for both types of capacitors is in the range from 0.5 to $0.6 \mathrm{eV}$, so $E_{v}$ is $\sim 1.1 \mathrm{eV}$. The latter value is close to the range of values reported previously. Based on the rate of annealing and measurements of the thermally stimulated depolarization (TSD), the activation energy for mobility of $\mathrm{V}_{\mathrm{o}}^{++}$was 1.1 to $1.2 \mathrm{eV}[5,17]$. Analysis of local atomic structure before and after annealing in thin $(\sim 100 \mathrm{~nm})$ amorphous Ta2O5 layers showed that activation energy of oxygen diffusion via vacancies is in the range from 1 to $1.3 \mathrm{eV}$ [19]. Interestingly, $E_{a}$ for diffusion of oxygen ions in ceramic capacitors has similar values, from 0.9 to $1.1 \mathrm{eV}$ [20].

The range of activation energies observed in this work for type II failures is overlapped by values reported for type I failures. Although more data are necessary to reveal possible differences, both types of failures are associated with ionic processes, and thus might have similar activation energies and acceleration factors.

The suggested mechanism can explain a correlation observed between the minimal, or initial, leakage currents and the rate of degradation (Figure 4). Capacitors with higher concentration of $\mathrm{V}_{\mathrm{o}}^{++}$would have a greater degradation rate and higher levels of initial leakage currents because the stresses that parts experienced during manufacturing testing (e.g. burningin) could cause a certain level of degradation before HALT. It is also possible that oxygen vacancies being donors for electrons would increase conductivity of the dielectric and greater DCL.

The presence of low- and fast-degrading subgroups in the population of $6.8 \mu \mathrm{F} 25 \mathrm{~V}$ capacitors might be due to a poor reproducibility of the anodic oxidation process that causes variations in conditions at the surface of the tantalum pellet after sintering. Similar bimodal distributions of TTF for metalinsulator-metal (MIM) capacitors with deposited Ta2O5 dielectric was observed in $[8,21]$. The results were explained by the presence of two failure mechanisms: thermal runaway for capacitors having low TTF, and intrinsic wear-out for capacitor failing at times that are more than two orders of magnitude greater.

Our data show that the fast degrading capacitors failed parametrically, without thermal runaway. Due to saturation of leakage currents with time, there might be no catastrophic failures if testing continued. More than that, samples in the slow degrading subgroup might not fail even parametrically. However, this does not exclude the possibility that another 
mechanism, e.g. TDDB or field induced crystallization, would cause failures if duration of testing is increased substantially. A reason for decreasing of the degradation rate with time might be a limited concentration of $\mathrm{V}_{\mathrm{o}}^{++}$in the oxide, or compensation of the positive charge by electrons or oxygen atoms injected from the $\mathrm{MnO} 2$ cathode layer [22].

\section{REFERENCES}

1 B. Goudswaard and F. J. J. Dreisens, "Failure mechanism of solid tantalum capacitors," Electrocomponent Science and Technology, vol. 3, pp. 171-179, 1976.

2 T. Tripp and Y. Freeman, Major Degradation Mechanisms in Tantalum and Niobium Based Capacitors: Components Technology Institute Inc., 2008.

3 A. Teverovsky, "Scintillation Breakdowns and Reliability of Solid Tantalum Capacitors," IEEE Transactions on device and materials reliability, vol. 9, pp. 318-324, 2009.

4 T. Zednicek, J. Sikula, and H. Leibovitz, "A Study of Field Crystallization in Tantalum Capacitors and its effect on DCL and Reliability," presented at the 29th symposium for passive components, CARTS'09, Jacksonville, FL, March 30 - April 2, pp.5.3.1-11, 2009.

5 A. Teverovsky, "Degradation of leakage currents in solid tantalum capacitors under steady-state bias conditions," in Electronic Components and Technology Conference (ECTC), 2010 Proceedings 60th, 2010, pp. 752-757.

6 A. Teverovsky, "Analysis of Weibull Grading Test for Solid Tantalum Capacitors," in CARTS Europe, Munich, Ge, 2010, pp. 103-120.

7 A. Teverovsky, "Voltage Acceleration Factors for Infant Mortality Failures and Derating of Solid Tantalum Capacitors," in 2013 Workshop on Accelerated Stress Testing \& Reliability (ASTR), San Diego, CA, 2013.

8 T. Remmel, R. Ramprasad, and J. Walls, "Leakage behavior and reliability assessment of tantalum oxide dielectric MIM capacitors," in Reliability Physics Symposium Proceedings, 2003. 41st Annual. 2003 IEEE International, 2003, pp. $277-$ 281.

9 A. Teverovsky, "Evaluation of Microchip Tantalum Capacitors," in CARTS International, Las Vegas, NV, 2012, pp. 195-207.

10 J. L. Paulsen, "Reliability Characterization of Tantalum Capacitors with MnO2 Counter-Electrode," in CARTS Europe: 24th Annual Capacitor and Resistor Technology Symposium, Bad Homburg, Germany, 2006.

11 C. Reynolds, "Reliability management of tantalum capacitors," AVX Technical information.

12 S. D. Khanin, "Electrical destruction of amorphous tantalum and niobium oxide films," in Proceedings of the 4th International Conference on Conduction and Breakdown in Solid Dielectrics, 1992, pp. 528-532.

13 KEMET. 2006, Tantalum High Reliability Capacitors. Available:

http://www.kemet.com/Lists/ProductCatalog/Attachments/ 29/F3113_Mil_TA_High_Rel.pdf

14 HITACHI. Precautions in using Tantalum Capacitors. Available: http://www.hitachiaic.com/docs/products/tantprecautions.p df

15 NEC/TOKIN. Product catalog. Available: www.nectokin.com/english/product/pdf_dl/capacitors_db.pdf

16 V. A. Laleko, L. L. Odinets, and G. B. Stefanovich, "Ionic current and kinetics of "activation" of the conductivity (degradation) of anodic oxide films on tantalum in strong electric fields," Soviet Electrochemistry, vol. 18, pp. 743 746, 1982.

17 A. Teverovsky, "Effect of Post-HALT Annealing on Leakage Currents in Solid Tantalum Capacitors," in CARTS USA, New Orleans, LA, 2010.

18 R. M. Fleming, D. V. Lang, C. D. W. Jones, M. L. Steigerwald, D. W. Murphy, G. B. Alers, et al., "Defect dominated charge transport in amorphous Ta2O5 thin films," Journal of Applied Physics, vol. 88, pp. 850-862, 2000.

19 R. Nakamura, T. Toda, S. Tsukui, M. Tane, M. Ishimaru, T. Suzuki, et al., "Diffusion of oxygen in amorphous Al2O3, Ta2O5, and Nb2O5," Journal of Applied Physics, vol. 116, p. 033504, 2014.

20 S. Zafar, R. E. Jones, B. Jiang, B. White, P. Chu, D. Taylor, et al., "Oxygen vacancy mobility determined from current measurements in thin $\mathrm{Ba} 0.5 \mathrm{Sr} 0.5 \mathrm{TiO} 3$ films," Applied Physics Letters, vol. 73, pp. 175-177, Jul 1998.

21 K. H. Allers, R. Schwab, W. Walter, M. Schrenk, and H. Korner, "Thermal and dielectric breakdown for metal insulator metal capacitors (MIMCAP) with tantalum pentoxide dielectric," in IEEE International Integrated Reliability Workshop Final Report, 2002, pp. 96-101.

22 B. T. Boiko, V. R. Kopach, S. M. Melentjev, P. A. Pachena, Y. L. Pozdeev, and V. V. Starikov, "Comparison of the degradation modes in sandwich structures including amorphous oxides of niobium and tantalum," Thin solid films, vol. 229, pp. 207-215, 1993.

\section{ACKNOWLEDGMENT}

This work was sponsored by the NASA Electronic Parts and Packaging (NEPP) program. The authors are thankful to Michael Sampson, NEPP Program Manager, for support of this investigation, Bruce Meinhold, AS\&D Group Lead, for a review and discussions.

\section{BIOGRAPHIES}

Alexander Teverovsky, ASRC/GSFC code 562.

Greenbelt, MD 20771 USA

Alexander.a.teverovsky@nasa.gov

Alexander Teverovsky received Ph.D in electrical engineering from Moscow University of Electronic Machine Building, Russia. Dr. Teverovsky jointed Goddard Space Flight Center Parts Analysis lab in 1994 as a senior failure analyst performing failure analysis, design and reliability evaluations of hybrids, microcircuits, and discrete active and passive components. Starting in 2000, he is working on evaluation of variety of new technologies and devices for space applications. Recent research interests include reliability and qualification of new technology ceramic and tantalum capacitors. 